\title{
Spectrin and Calmodulin in Spreading Mouse Blastomeres
}

\author{
J. Sabina Sobel, ${ }^{*}$ Elaine G. Goldstein,* Judith M. Venuti, $†$ and Michael J. Welsh \\ *Department of Anatomical Sciences, State University of New York at Buffalo, Buffalo, New York 14214; †Department of Zoology, University \\ of Texas, Austin, Texas 78712; $\ddagger$ Department of Anatomy and Cell Biology, University of Michigan School of Medicine, Ann Arbor, Michigan 48109
}

Accepted November 9, 1987

\begin{abstract}
The role of spectrin and its association with calmodulin in spreading mouse blastomeres was investigated. Embryonic spectrin binds ${ }^{125}$ I-calmodulin in a calcium-dependent fashion in the blot overlay technique. Double-labeling experiments show coordinate redistribution of spectrin and calmodulin in blastomeres preparing to undergo active spreading movement. At this stage cortical spectrin staining is lost from the region of cell-substrate contact and spectrin and calmodulin become concentrated in two structures closely associated with the contacted region: a group of spherical bodies located on the cytoplasmic side of the cortical layer and a subcortical ring that marks the perimeter of the contacted region. The localization pattern of spectrin and calmodulin is also coordinated with that of actin and myosin. The results suggest that spectrin plays a role in the spreading of blastomeres and that this function may involve linkage of spectrin, calmodulin, and the cortical contractile apparatus. of 1988 Academic Press, Inc.
\end{abstract}

\section{INTRODUCTION}

A spectrin-like protein has recently been identified in the preimplantation mouse embryo (Damjanov et al., 1986; Reima and Lehtonen 1985; Sobel and Alliegro, 1985; Schatten et al., 1986) which undergoes developmentally related changes in distribution from the egg to the blastocyst stage (Schatten et al., 1986; Sobel and Alliegro, 1985).

Spectrin can be expected to play a role in early development for the following reasons: (1) Spectrin is implicated in the control of cell shape and shape transformation (Branton 1981; Lux, 1979). (2) Nonerythroid, like erythroid, spectrin binds calmodulin in a calcium-sensitive fashion (Glenney et al, 1982; Kakiuchi et al., 1982; Palfrey et al., 1982). Calmodulin is an intracellular receptor for calcium that mediates important cellular reactions (Cheung, 1980; Means and Dedman, 1980) including some that are involved in preimplantation development (Bilozur and Powers, 1982; Pakrasi and Dey, 1984). (3) Nonery throid, like erythroid, spectrin binds to and crosslinks actin filaments (Bennet et al., 1982; Burridge et al., 1982; Glenney et al., 1982; Hirokawa et al., 1983; Howe et al., 1985) and can modulate the interaction of actin and myosin in a calcium-sensitive fashion (Shimo-Oka and Watanabe, 1981; Wagner, 1984). Actin (Johnson and Maro, 1984; Sutherland and Calarco-Gillam, 1983) and myosin (Sobel, 1984a) are both implicated in preimplantation development.

The present study was designed to test the hypothesis that spectrin plays a role in cell contact interactions and spreading in mouse blastomeres (Sobel and Alliegro, 1985.) We utilized a model system in which two-cell embryos cultured on concanavalin A (Con A)-coated coverslips undergo spreading movements and changes in cytoskeletal organization that resemble changes which occur during cell-cell interaction in the embryo (Kimber and Surani, 1982; Sobel, 1984a). The results indicate that there is a spatial and temporal relationship between spectrin distribution and the potential of blastomeres to spread, that embryonic spectrin can bind calmodulin in a calcium-sensitive fashion, and that the distribution of spectrin is related to that of calmodulin and the intracellular contractile apparatus.

\section{METHODS}

\section{Collection and Culture of Embryos}

Preimplantation mouse embryos were obtained from 6- to 8-week-old ICR females (West Seneca Breeding Facility, Roswell Park Memorial Institute, Buffalo, NY). The animals were superovulated with iv injections of 5 IU each of pregnant mare's serum (Gestyl, Diosynth, Chicago, IL) followed by human chorionic gonadotrophin (hCG) (APL, Ayerst, NY) $48 \mathrm{hr}$ later and mated with $\mathrm{CB}_{6} \mathrm{Fl} / \mathrm{J}$ males (Jackson Labs, Bar Harbor, ME).

Two-cell embryos were recovered from the oviducts $42 \mathrm{hr}$ post-hCG. The embryos were cultured as described previously (Sobel 1984a), harvested at the hatched blastocyst stage, washed with $0.4 \%$ polyvinylpyrrolidone in Hanks' balanced salt solution (HBSS) and suspended in sample buffer for electrophoresis (Sobel and Alliegro, 1985).

Coverslip cultures of two-cell embryos were prepared as described previously (Sobel, 1984a). Acid cleaned No. 1 coverslips were incubated with $5 \mathrm{mg} / \mathrm{ml}$ Con A 
(Sigma) in HBSS for $2 \mathrm{hr}$, rinsed in $\mathrm{H}_{2} \mathrm{O}$, covered with a drop of modified egg culture medium (Spindle, 1980) and preequilibrated at $\mathrm{pH} 7.3$ at $37^{\circ} \mathrm{C}$. Embryos were treated with acid Tyrode's to remove the zona pellucida, immediately transferred to a dish of preequilibrated medium, and precultured for $1 \mathrm{hr}$. The embryos were then transferred to the coverslips and cultured for 4.5 hr (44-48.5 hr post-hCG).

\section{Purification of Mouse Brain $\alpha$-Spectrin}

Adult mice were anesthetized with pentobarbitol and perfused through the heart with saline, and the brains were removed and frozen in ethanol cooled with dry ice. Spectrin was purified from 10-g samples of brain by gel filtration on Sepharose 4B and the eluant fractions, enriched for spectrin, were subjected to preparative $4 \%$ SDS-PAGE as described by Levine and Willard (1981).

\section{Preparation of Brain Fractions and Erythrocyte Membranes}

Cytoskeletal fractions of mouse brain enriched for spectrin were prepared according to Palfrey et al. (1982). Chicken erythrocyte membranes were isolated as described previously (Sobel and Alliegro, 1985). Aliquots were suspended in sample buffer and stored at $-70^{\circ} \mathrm{C}$.

\section{Antibody Production}

Antiserum against mouse brain $\alpha$-spectrin was raised in rabbits. Bands of $\alpha$-spectrin were excised from $4 \%$ acrylamide gels, homogenized, and injected according to the protocol described previously (Sobel and Alliegro, 1985). IgG fractions were partially purified by fractionation with $\mathrm{NH}_{4} \mathrm{SO} 4$ at $50 \%$ saturation.

Affinity-purified antibody to mouse brain $\alpha$-spectrin was prepared by adsorption of antiserum to homogenized bands of $\alpha$-spectrin that were used as an affinity matrix (Mangeat and Burridge, 1984).

Calmodulin antibody was raised against bovine testis in a sheep and was affinity-purified as previously described (Dedman et al, 1978).

\section{Electrophoresis}

Protein samples were analyzed by SDS-PAGE using the Tris-glycine buffer system of Laemmli (1970). The running gel contained $10 \%$ acrylamide and $0.13 \%$ $N, N^{\prime}$-methylene bisacrylamide; the stacking gel contained $5 \%$ acrylamide and $0.13 \% N, N^{\prime}$-methylene bisacrylamide.

\section{Transfer to Nitrocellulose}

Protein subjected to SDS-PAGE was stained with Coomassie blue or electrophoretically transferred to nitrocellulose sheets according to Towbin et al. (1979). The blotting buffer contained $25 \mathrm{~m} M$ Tris, $192 \mathrm{mM}$ glycine, $20 \%$ methanol, and $0.1 \%$ SDS (Sobel and Alliegro, 1985).

\section{Immunological Detection of Spectrin on Nitrocellulose}

Blots were washed in $10 \mathrm{~m} M$ sodium phosphate, $0.9 \%$ $\mathrm{NaCl}(\mathrm{pH} \mathrm{7.5)}$ in PBS with Tween 20 (TPBS) and 5\% (w/v) Carnation milk (Johnson et al, 1984), incubated with antibody (1:125 dilution) in TPBS, and washed three times in TPBS. Antibody binding was detected by immunoperoxidase staining using the Vectastain $\mathrm{ABC}$ Kit (Vector Laboratories, Inc., Burlingame, CA) according to the manufacturer's instructions. Because of the large number of embryos required to obtain visible bands, only immunoblots and no Coomassie bluestained gels were prepared from blastocysts.

\section{Detection of ${ }^{125}$ I-Calmodulin Binding to Spectrin by the Blot-Overlay Technique}

Bovine brain calmodulin (Sigma) was iodinated by the method of Bolton and Hunter (1973) and calmodulin was separated from reactants by chromatography on a Sephadex G-25 column. Blot-overlays were performed as described by Flanagan and Yost (1984) in buffer A containing $50 \mathrm{mM}$ Tris, $\mathrm{pH} 7.6,0.2 \mathrm{M} \mathrm{NaCl}, 1 \mathrm{mM} \mathrm{CaCl}$, and $0.05 \%$ Tween 20 as a quenching agent. Blots were treated for $3 \mathrm{hr}$ in buffer A, incubated for $75 \mathrm{~min}$ with ${ }^{125} \mathrm{I}$-calmdulin in buffer $\mathrm{A}$, and washed $4 \times$ with 15 -min washes in Buffer A. Blots were then dried overnight and autoradiographed on Kodak XAR film with a Picker rare earth intensifying screen at $-80^{\circ} \mathrm{C}$. Molecular weights were calculated using either cold standards in stained gels or in blots stained with India ink.

\section{Immunofluorescent Localization of Spectrin, Actin, Myosin, and Calmodulin}

Cytoskeletal preparations of two-cell embryos attached to Con A-coated coverslips were prepared as described previously (Sobel, 1984a). Each labeling protocol was repeated at least three times with a minimum of 20 embryos per group. The embryos were permeabilized with $0.02 \%$ saponin in stabilization buffer, fixed in cold methanol, rinsed in PBS with 0.4\% PVP, transferred to PBS, and stained for spectrin, myosin, and calmodulin by indirect immunofluorescence in PBS with $0.02 \%$ saponin. Antibodies used were affinity-purified antibody to mouse brain $\alpha$-spectrin $(90 \mu \mathrm{g} / \mathrm{ml})$; affinity-purified 
sheep antibody to bovine testis calmodulin $(200 \mu \mathrm{g} / \mathrm{ml})$ (Dedman et al., 1978); and rabbit antiserum to human platelet myosin (Fujiwara and Pollard, 1976) provided by K. Fujiwara which stains myosin specifically (Sobel, 1984a). Fluoresceinated rabbit anti-sheep IgG and fluoresceinated goat anti-rabbit IgG (Antiibodies, Ine., Davis, CA) were preabsorbed with mouse tissues and diluted $1: 10$ and 1:40, respectively. For double-labeling experiments the embryos were stained for actin with rhodamine-phalloidin (1:10; Molecular Probes, Eugene, OR). After extensive washing the embryos were mounted in Elvanol, examined in an inverted Zeiss photomicroscope with a Planapo $63 \mathrm{X}$ objective, and photographed with Kodak Tri-X film which was developed in Microdol X.

\section{RESULTS}

\section{Immunofluorescent Localization of Spectrin, Actin, Myosin, and Calmodulin}

The specificity of the antibody to mouse brain $\alpha$ spectrin $(240,000 \mathrm{MW})$ and its eross-reactivity with avian erythrocyte $\alpha$-spectrin $(240,000 \mathrm{MW})$ and a comigrating polypeptide in mouse blastocyst are shown in Fig. 1.

Blastomeres are characterized by the presence of a submembranous layer of spectrin (Damjanov et al.,

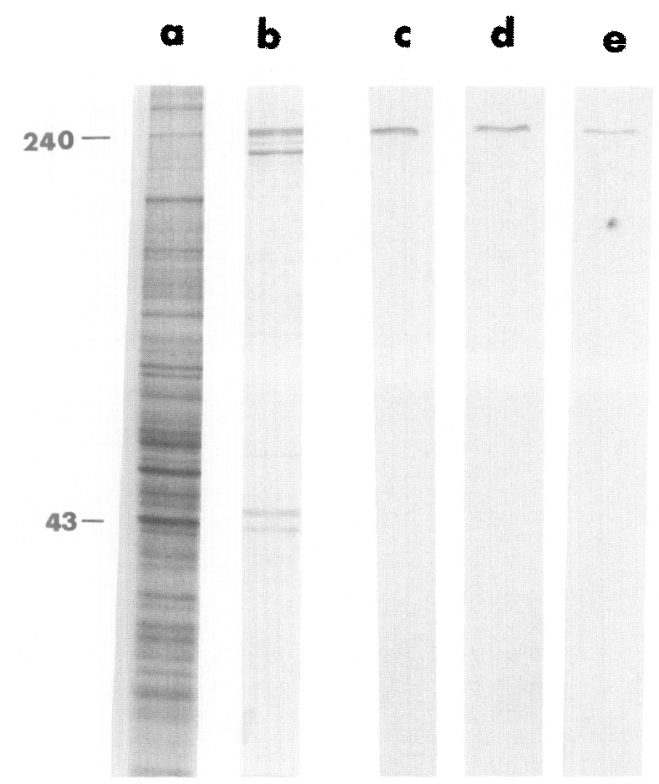

FIG. 1. Immunological cross-reaction of mouse brain, avian erythrocyte, and mouse blastocyst $\alpha$-spectrin. Coomassie blue staining pattern of mouse brain (a) and avian erythrocyte ghosts (b) separated on $10 \%$ SDS-PAGE. Numbers indicate molecular weights $\times 10^{-3}$ of protein standards. Western blots of brain (c), erythrocyte ghosts (d) and blastocysts (e) exhibit bands with the same mobility as $\alpha$-spectrin. Lane $\mathrm{e}$ is derived from 870 embryos.
1986; Reima and Lehtonen, 1985; Schatten et al., 1986; Sobel and Alliegro, 1985). Standard procedures for immunofluorescent localization of cortical proteins provide limited information about spectrin organization in the region of cell-cell contact because embryos are generally viewed perpendicularly to the plane of contact (Fig. 3). In order to obtain an en face view of the contacted region of the blastomeres we utilized a model system in which two-cell embryos are cultured on Con A-coated coverslips (Fig. 2) (Sobel, 1984a). These substrate-bound embryos undergo active spreading movements and cytoskeletal reorganization that mimic the behavior of blastomeres in the embryo (Kimber and Surani, 1982; Kimber et al., 1982; Sobel, 1984a). An additional advantage of the model system is that cells can be monitored throughout the course of contact development and spreading. Since previous studies suggested that spectrin localization may be related to an enhanced potential for contact interaction (Sobel and Alliegro, 1985) we focused on the stage when the substrate-bound cells have acquired the potential to spread but have not yet undergone extensive spreading movements. This occurs between $4-5 \mathrm{hr}$ in culture (44-49 hr post-hCG) (Sobel, 1984a).

Figure 4 illustrates the distribution of spectrin in a substrate-bound embryo with the focus on the plane of contact. There is weak cortical staining in contacted regions and bright fluorescence in small spherical bodies and in a ring-like structure around the perimeter of the contacted areas. The spherical bodies and the cytoskeletal ring are both located subjacent to the cortical layer on the cytoplasmic side. The specificity of the staining reaction is demonstrated by the absence of staining in preabsorption controls (Fig. 8).

The embryos in Figs. 5 and 6 were double-labeled in order to identify the simultaneous distribution patterns of spectrin, actin, and myosin, and the embryo in Fig. 5 was compressed between the coverslip and slide to expose more of the uncontacted parts of the cells. Embryos double-labeled for actin (with rhodamine-phalloidin) (Fig. 5a) and spectrin (Fig. 5b), and embryos double-labeled for actin (Fig. 6a) and myosin (Fig. 6b), show identical distribution patterns. The uncontacted region of the blastomeres is characterized by a prominent cortical staining reaction for spectrin, actin, and myosin. The contacted region shows coordinated redistribution of spectrin, actin, and myosin with loss of cortical staining in the contacted area and concentrations of the three proteins in the spherical bodies and in the ring that marks the perimeter of the contacted region. This pattern was observed in $90-100 \%$ of the embryos in each experiment.

The reorganization of the cytoskeletal cortex can also 


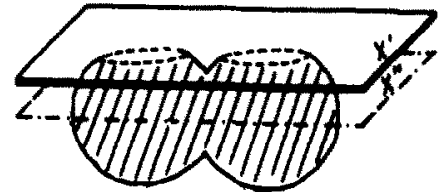

2
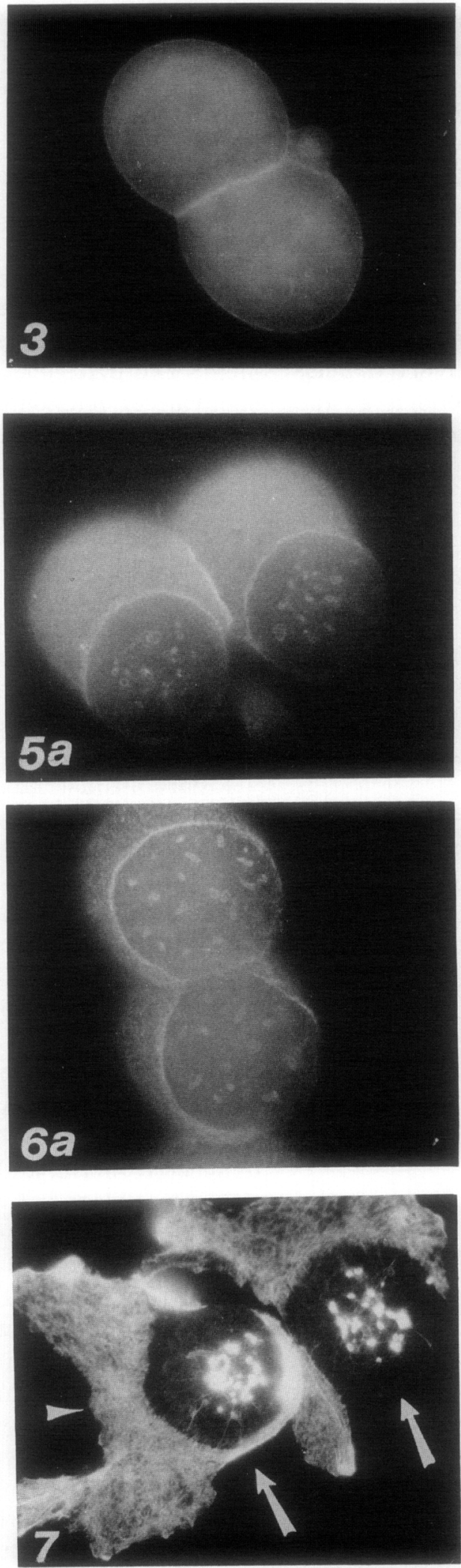
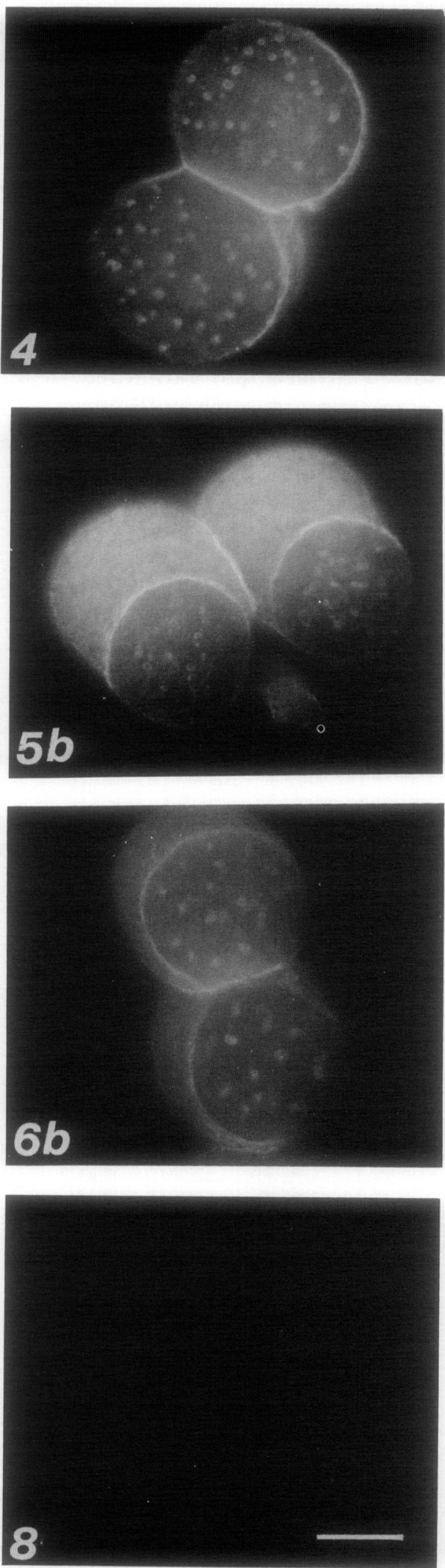

FIGS. 2-8. Localization of spectrin, actin, and myosin in two-cell embryos cultured for $4.5 \mathrm{hr}$ on Con A-coated coverslips.

Fig. 2. Diagram illustrates the planes of focus: Contact region, plane X'; embryo midsection, plane $X^{\prime \prime}$. Hatched areas indicate positive staining; clear areas indicate an absence or reduced staining. The broken line marks the locus of the cytoskeletal ring.

Fig. 3. Embryo stained for spectrin with the focus on the plane of midsection shows fluorescence in the cortical regions.

Figs. 4-8. Focus in the contact region. 
be demonstrated in "cortical lawns." In these preparations the substrate-bound embryo is sheared off, leaving the membrane with its associated filaments attached to the coverslip (Sobel, 1984b). Remnants of the uncontacted cell periphery sometimes remain attached to the lawn and this allows direct comparison of the inner face of the cortex in the contacted and uncontacted parts of the cell (Fig. 7). When stained for actin the cortex associated with the uncontacted region appears as a thick meshwork of actin filaments (Fig. 7, arrowhead). The filamentous lawn associated with the contacted region gives a much weaker staining reaction (Fig. 7, arrows) and these filaments are intimately associated with some of the smaller spherical bodies.

Embryos labeled for calmodulin usually exhibited diffuse intracellular fluorescence with no detectable concentration of calmodulin in the cortical layer, as shown in the embryo double-labeled for actin (Fig. 9a) and calmodulin (Fig. 9b). A minority of the embryos showed regional concentrations of calmodulin which took the form of cortical bands in the polar body (Fig. 10), punctate nuclear concentrations (Fig. 10), and cortical caps in one or both blastomeres (Fig. 11).

Embryos cultured on coverslips exhibited a consistent reorganization of calmodulin in the contact region. This is illustrated in an embryo double-labeled for actin and calmodulin (Figs. 12a and 12b) which shows, against a background of diffuse interior staining, a ring of calmodulin around the contact region. The diffuse interior staining is characteristic of intact cells and is specific for calmodulin (Fig. 14). It is absent from membrane lawns and the improved resolution in these preparations shows that calmodulin colocalizes with actin in at least some spherical bodies as well as in the cytoskeletal ring (Figs. 13a and 13b).

\section{${ }^{125}$ I-Calmodulin Binding to Spectrin}

Blastocysts were compared for their ability to bind ${ }^{125}$ I-calmodulin with avian erythrocyte ghosts and a fraction of mouse brain enriched for spectrin by the ${ }^{125}$ I-calmodulin blot-overlay technique. Interaction of ${ }^{125} \mathrm{I}$-calmodulin with a $240,000 \mathrm{MW}$ polypeptide was found in brain, erythrocytes, and blastocysts (Fig. 15, lanes c, $d$, and e). The autoradiogram was exposed for 27 hr, 3 days, and 8 days for the erythrocyte, brain and blastocyst samples, respectively, to obtain optimal resolution of the $240,000 \mathrm{MW}$ band. Because of the large number of embryos required for this assay (approximately 2000) the sensitivity of this reaction to calcium was tested by a subsequent incubation of the same blot in calcium-free buffer. As shown in Fig. 1, lanes $f, g$, and $\mathrm{h}$, the binding of ${ }^{125} \mathrm{I}$-calmodulin was eliminated in the absence of calcium in each sample. Blastocysts also showed bands that bound ${ }^{125}$ I-calmodulin in a calciumdependent manner with molecular weights of approximately $210,000,170,000,72,000,40,000-50,000,20,000$, and 12,000 .

\section{DISCUSSION}

This study was designed to investigate the role of spectrin in spreading blastomeres. Because of the difficulties in visualizing contacted regions in the intact embryo we utilized a model system in which blastomeres spread on Con A-coated coverslips. Spreading behavior on the Con A-coated substrate is similar to that on other substrate-bound lectins (Kimber and Surani, 1982; Sobel, 1984a) and can also be evoked by physical stress on cells attached to untreated coverslips (J. S. Sobel, unpublished experiments). Substratebound Con A thus seems to stimulate a form of "standard" spreading response to artificial substrates.

Spreading in the embryo is associated with compaction, a process that takes place at the 8-cell stage and is thought to have an important influence on blastocyst formation (Johnson, 1979). The spreading movements of blastomeres on Con A-coated substrate and the associated changes in cytoskeletal organization appear to mimic the behavior compacting cell in the embryo (Kimber and Surani, 1982; Kimber et al., 1982; Sobel, 1984a). Moreover, blastomeres of two-cell embryos can be induced to spread like those of eight-cell embryos on artificial substrates (Sobel, 1984a). Blastomeres from two-cell rather than eight-cell embryos were utilized for these experiments for the following reasons: (1)

FIG. 4. Embryo stained for spectrin with the focus on the plane of cell-substrate contact shows weak cortical staining in the contact region and bright fluorescence in spherical bodies and in rings that delimit the edge of contacted regions.

FIG. 5. Embryo double-labeled for actin (5a) and spectrin (5b) was compressed between the coverslip and slide to expose more of the uncontacted region of the cells. Actin and spectrin show coordinate distribution with prominent cortical layers in uncontacted regions, loss of staining in contacted regions, and double-labeling of the spherical bodies and surrounding rings.

FIG. 6. Embryo double-labeled for actin (6a) and myosin (6b) shows coordinate distribution of both proteins with the same pattern as in the embryo in Fig. 5.

FIG. 7. Membrane lawn stained for actin. Membrane associated filaments in the contacted regions give a weak staining reaction (arrows), whereas remnants of the cortex from uncontacted parts of the cells show bright fluorescence (arrowhead). Subcortical spherical bodies associated with the contact region (bright spots) are out of the plane of focus.

FIG. 8. Control embryo treated with preabsorbed antibody to spectrin shows no staining reaction. Bar equals $20 \mu \mathrm{m}$. 

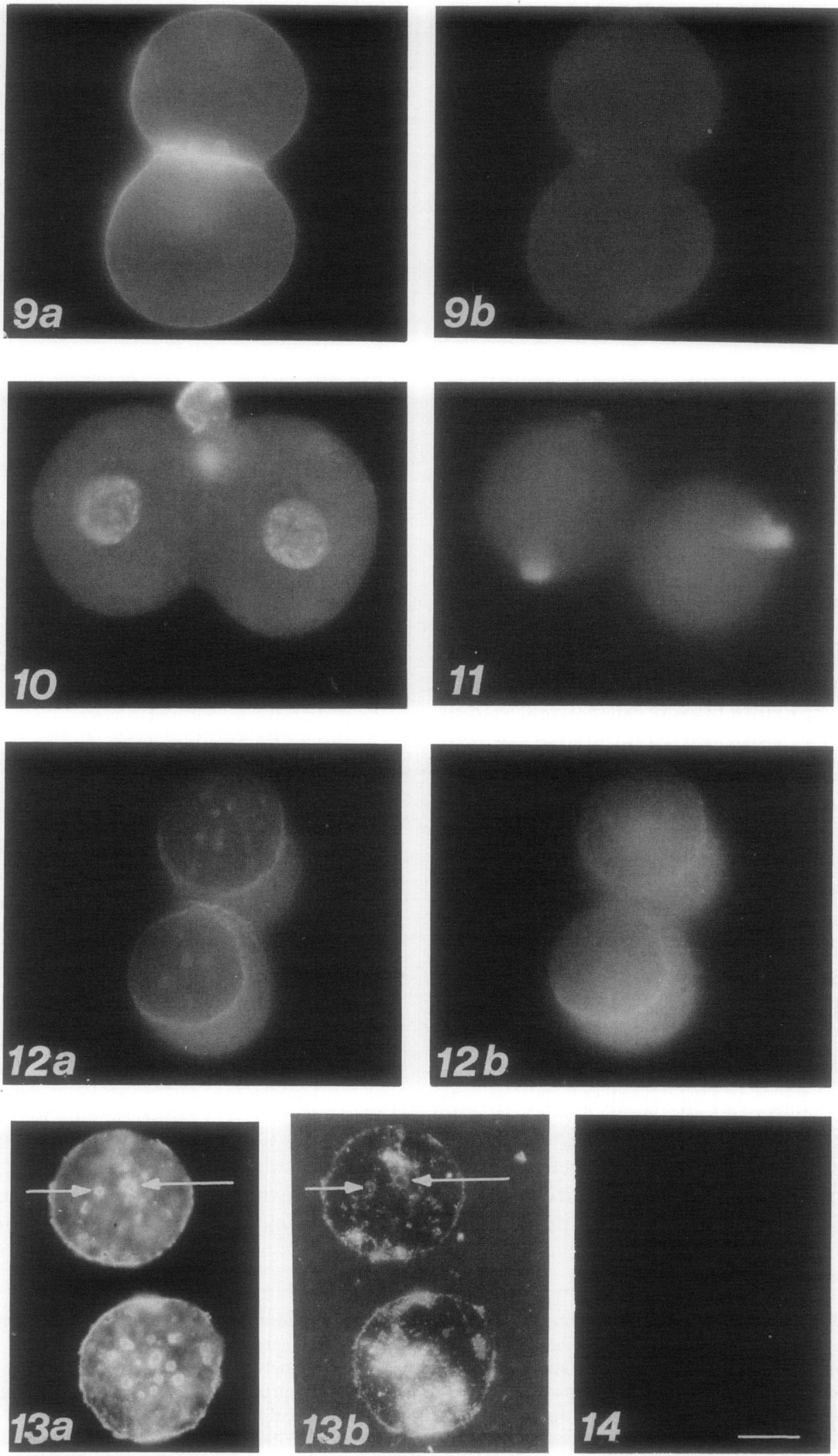

FIGS. 9-14. Localization of actin and calmodulin in 2-day embryos cultured for $4.5 \mathrm{hr}$ on Con A-coated coverslips.

FIG. 9. Embryo double-labeled for actin (9a) and calmodulin (9b), with the focus on the plane of the embryo midsection. Calmodulin shows a diffuse distribution with no peripheral concentration like that of actin.

FIG. 10. Embryo stained for calmodulin with the focus on the plane of the embryo midsection. Nuclei and the cortex of the polar body show bright fluorescence. 


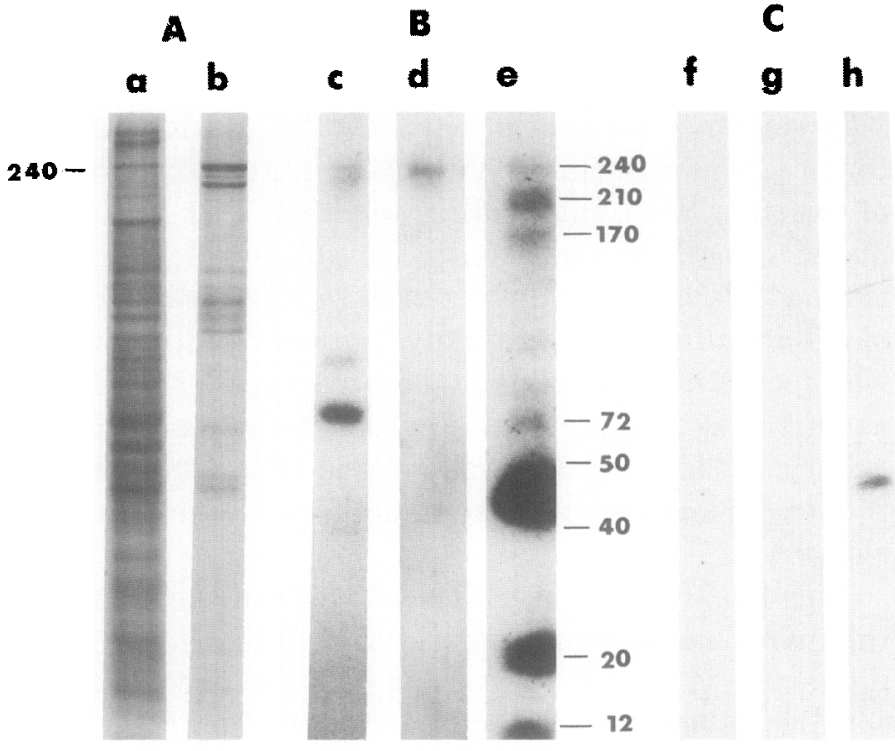

FIG. 15. Detection of calmodulin binding proteins in mouse brain, avian erythrocyte ghosts and blastocysts. (A) Coomassie blue staining of proteins separated on $10 \%$ SDS-PAGE. (B, C) Autoradiogram of a blot first incubated in the presence of $1 \mathrm{mM}$ calcium (B) and then in the absence of calcium (C). Lanes (a, c, f) Mouse brain. Lanes $(b, d, g)$ Erythrocyte ghosts. Lanes (e, h) Blastocysts. Numbers indicate molecular weights $\times 10^{-3}$ of protein standards. Embryo spectrin, like brain spectrin and avian ery throeyte $\alpha$-spectrin, bound calmodulin in a calcium-sensitive fashion.

Their long interphase (approximately $12 \mathrm{hr}$ under these culture conditions) ensures sufficient time to recover from the acid Tyrode's used to remove the zona pellucida. This treatment has profound effects on cytoskeletal organization (Sobel, 1983). (2) The long interphase also provides sufficient time to study the spreading phenomenon and the associated cytoskeletal changes without the complications of cell division. (3) Blastomeres of two-cell embryos have a thicker cortex than those of eight-cell embryos which allows much better resolution of immunofluorescent staining patterns.

Two-cell blastomeres develop stable cell-substrate contacts, as defined by resistance to detachment by Triton $\mathrm{X}-100$, by the fourth $\mathrm{hr}$ of culture and spread by lamellipodial projections by $6 \mathrm{hr}$ (Sobel, 1984a). In this study we focused on the stage preceding extensive spreading movements $(4.5 \mathrm{hr}$ ) because previous studies suggested that spectrin distribution may be related to the state of activation of the cell periphery (Sobel and
Alliegro, 1985). We define activation in this system as the potential to undergo spreading.

\section{Spectrin Distribution and Blastomere Activation}

Substrate-bound blastomeres exhibited a consistent redistribution of cortical spectrin by $4.5 \mathrm{hr}$ in culture with loss of spectrin staining in the contact region and development of spectrin-containing spherical bodies and a ring around the contacted area. Previous studies utilizing interference reflection microscopy showed that contacted regions in 4-6 hr cultures are characterized by a uniform mosaic pattern of close and far contacts (Sobel et al., 1985). Such close contacts between the basal surface of cells and the substratum are specifically associated with spreading processes (Izzard and Lochner, 1980; Keller et al., 1979). The substrate-bound blastomeres also exhibit extensive reorganization of membrane-associated actin filaments in the contact region (Fig. 7). Similar changes are associated with the development of a motile cytoplasm in other cell types (Bereiter-Hahn et al., 1979). This spatial and temporal correlation between spectrin distribution and development of a motile cytoplasm suggest that spectrin may be involved in processes related to peripheral activation. Such a role is consistent with the evidence indicating that development of the preimplantation embryo, from the egg through the blastocyst stage, is characterized by loss of cortical spectrin staining and peripheral activation, on the one hand, and positive cortical staining and peripheral stability, on the other hand (Sobel and Alliegro, 1985).

\section{Association of Spectrin with Actin and Myosin}

Blastomeres have a prominent cortical layer that stains for actin (Johnson and Maro, 1984; Lehtonen and Badley, 1980) and myosin (Sobel 1984a) as well as spectrin. The 4.5 -hr cultures of substrate-bound blastomeres underwent coordinate redistribution of the three proteins causing the cell periphery to be partitioned into two domains, the uncontacted region that retains the cortical layer of proteins and the contacted region that exhibits loss of staining for the three proteins. A cytoskeletal ring marks the boundary between the two regions. Polarization of the cortical proteins was associated with two kinds of motile activity, the first in-

Fig. 11. Embryo stained for calmodulin with the focus on the plane of the embryo midsection shows asymmetric polarization in both blastomeres.

FIG. 12. Embryo double-labeled for actin (12a) and calmodulin (12b), focus in the plane of contact. Calmodulin colocalizes with actin in the ring surrounding the contact region.

Fig. 13. Substrate-bound remnant of an embryo that was double-labeled for actin (13a) and calmodulin (13b) and then detached from the coverslip. Focus is on the spherical bodies on the cytoplasmic side of the contact region which show colocalization of both proteins (arrows).

FIG. 14. Control embryo treated with preabsorbed antibody to calmodulin shows no labeling. Bar equals $20 \mu \mathrm{m}$. 
volving movement of spectrin, actin, and myosin in the cortical compartment; the second becoming manifest when the three proteins are cleared from the contact region and the underlying cytoplasm extends lamellipodial projections (Sobel, 1984a). The influence of spectrin on peripheral activation may thus be related, at least in part, to its linkage with the cortical contractile apparatus. Nonerythroid spectrin can mediate the linkage of actin filaments to each other (Bennet et al., 1982; Burridge et al., 1982; Glenney et al, 1982; Hirokawa et al., 1983; Howe et al., 1985) and to the membrane (Hirokawa et al., 1983; Mangeat and Burridge, 1983) and could thus influence peripheral stability by maintaining the structural integrity of the contractile apparatus and/or its association with the membrane. Spectrin can also influence the interaction of actin and myosin by modulating the activity of actin-activated myosin ATPase (Shimo-Oka and Watanabe, 1981; Wagner, 1984). In this view the loss of spectrin staining in the contacted region of the cell could be related to displacement or inactivation of the actomyosin-based force generating system.

The cytoskeletal organization of the substrate-bound blastomeres mimics that of blastomeres that are spreading against each other during compaction. Compacting cells also develop a polarized distribution of actin (Reima and Lehtonen, 1985) and myosin (Sobel, 1984a) and form a cytoskeletal ring that stains for spectrin and actin (Reima and Lehtonen, 1985) as well as myosin (Sobel, 1984a). These similarities suggest that the spreading behavior of blastomeres on artificial substrate can serve as a useful model to study the spreading movements of compaction.

It is noteworthy that the pattern of cortical organization that characterizes activated blastomeres in vitro and in the embryo is also seen in capped lymphocytes. Binding of Con A to lymphocytes stimulates the movement of spectrin, actin, and myosin to one pole of the cell (Levine and Willard, 1983; reviewed in Bourguignon and Bourguignon, 1984) and, as in blastomeres, the pole that is cleared of cortical proteins becomes the site of active cytoplasmic protrusion. A cytoskeletal ring also marks the boundary between the rounded and spreading domains in lymphocytes (Lewis, 1931; reviewed in Loor, 1981). Levine and Willard $(1981,1983)$ have proposed that the coordinated movement of cortical spectrin, actin, and myosin in lymphocytes and in axonal transport may constitute a mobile lining for the plasmalemma. Such a dynamic flow of cortical actomyosin in blastomeres is an attractive notion because it can explain important features of epithelial development (Jacobson et al., 1986) including, presumably, that of the trophoblast.
Association of Spectrin with Calmodulin

Development of spreading potential in cultured blastomeres was associated with coordinate redistribution of spectrin with calmodulin, together with actin and myosin. While the possibility cannot be ruled out that the permeabilization procedures induce redistribution of calmodulin, it is noteworthy that calmodulin labeling was specifically associated with structures that develop at this stage, namely, the cytoskeletal ring and the spherical bodies in the contact area (Fig. 12b and 13b). A detailed analysis of these structures will be presented elsewhere.

Technical reasons precluded analysis of spectrin from the two-cell embryo in the ${ }^{125} \mathrm{I}$-calmodulin overlay technique and we tested blastocysts instead. The blastocyst spectrin, like other nonerythroid spectrins (Glenney et al., 1982; Kakiuchi et al., 1982; Palfrey et al., 1982), bound calmodulin in a calcium-sensitive fashion. It is tempting to speculate that spectrin-mediated reactions may be calcium-calmodulin regulated in the embryo.

There is indirect evidence to suggest that calmodulin may play a role in regulating the spreading behavior of blastomeres in situ. Calmodulin inhibitors can prevent compaction by influencing reactions that are sensitive to intracellular concentrations of calcium (Bilozur and Powers, 1982; Pakrasi and Dey, 1984). Moreover, the inhibitors appear to act specifically on the early stage of compaction (Bilozur and Powers, 1982) when the blastomeres are undergoing the first changes in cell shape and developing the potential to spread. Calmodulin has also been implicated in cell shape changes (Connor et al., 1981; Kao et al., 1981; Nelson et al., 1983) and spreading (Connor et al., 1981) in other cell types. The calcium-sensitive association of calmodulin with blastocyst spectrin and the coordinate redistribution of calmodulin with spectrin, actin, and myosin in the spreading two-cell blastomeres suggest that calmodulin could influence spreading behavior by regulating cytoskeletal interactions. Potential loci include regulation of membrane-cytoskeletal interactions (Connor et al., 1981), spectrin modulation of actin-activated myosin ATPase (Shimo-Oka and Watanabe, 1981; Wagner, 1984), and activation of myosin light chain kinase (Adelstein, 1982).

We thank Dr. K. Fujiwara for myosin antibody and Dr. P. CalarcoGillam and Dr. E. Koenig for critical readings of the manuscript. A preliminary report of this work was presented at the Annual Meeting of the American Society for Cell Biology, November 1986. This research was supported by National Institute of Health Grant R01-1869501A1 and National Science Foundation Grant UCB-8316683 awarded to J.S.S. and GM 33980 awarded to M.J.W. 


\section{REFERENCES}

AdELSTEIN, R. S. (1982). Calmodulin and the regulation of actinmyosin interaction in smooth muscle and nonmuscle cells. Cell 30 , $349-350$.

Bennet, V., DAvis, J., and Fowler, W. E. (1982). Brain spectrin, a membrane-associated protein related in structure and function to erythrocyte spectrin. Nature (London) 299, 126-131.

Bereiter-HAHN, J., FoX, C. H., and ThORELL, B. (1979). Quantitative reflection contrast microscopy of living cells. J. Cell Biol. 82, 767-779.

BiLozUR, M., and Powers, R. D. (1982). Two sites for calcium action in compaction of the mouse embryo. Exp. Cell Res. 142, 39-45.

Bolton, A. E., and HunTER, W. M. (1973). The labelling of proteins to high specific radioactivities by conjugation to an ${ }^{125} \mathrm{I}$-containing acylating agent. Biochem. J. 133, 529-539.

Bourguignon, L. Y. W., and Bourguignon, G. J. (1984). Capping and the cytoskeleton. Int. Rev. Cytol. 87, 195-224.

BRANTON, D. (1981). Erythrocyte membrane protein association and erythrocyte shape. Harvey Lect. 77, 23-42.

BurRIDGe, K., Kelly, T., and Mangeat, P. (1982). Nonerythrocyte spectrins: Actin-membrane attachment protein occuring in many cell types. J. Cell Biol. 95, 478-486.

CHEunG, W. Y. (1980). Calmodulin plays a pivotal role in cellular regulation. Science 207, 19-27.

Connor, C. G., Brady, R. C., and Brownstein, B. L. (1981). Trifluoperazine inhibits spreading and migration of cells in culture. $J$. Cell. Physiol 108, 299-307.

Damjanov, I., Damjanov, A., Lehto, V.-P., and Virtanen, I. (1986). Spectrin in mouse gametogenesis and embryogenesis. Dev. Biol. 114, 132-140.

Dedman, J. R., Welch, M. J., and Means, A. R. (1978). $\mathrm{Ca}^{2+}$-dependent regulator. Production and characterization of a monospecific antibody. J. Biol. Chem. 253, 7515-7521.

DUCiBELlA, T., and ANDERSON, E. (1975). Cell shape and membrane changes in the eight-cell mouse embryo: Prerequisite for morphogenesis of the blastocyst. Dev. Biol. 47, 45-58.

FlanaGaN, S. D., and Yost, B. (1984). Calmodulin-binding protein: Visualization by ${ }^{125}$ I-calmodulin overlay on blots quenched with Tween 20 or bovine serum albumin and poly (ethylene oxide). Anal Biachem. 140, 510-519.

FuJIWARA, K., and POLLARD, T. D. (1976). Fluorescent antibody localization of myosin in the cytoplasm, cleavage furrow and mitotic spindle of human cell. J. Cell Biol. 71, 846-857.

Glenney, J. R., Glenney, R., Osborn, M., and Weber, K. (1982). An $F$-actin and calmodulin-binding protein from isolated intestinal brush borders has a morphology related to spectrin. Cell 28, 843-854.

HirokaWA, N., ChENEY, R. E., and WillaRD, M. (1983). Localization of a protein of the fodrin-spectrin-TW $260 / 240$ family in the mouse intestinal brush border. Cell 32, 953-965.

Howe, C. L., SaCramone, L. M., Mooseker, M. S., and Morrow, J. S. (1985). Mechanism of cytoskeletal regulation: Modulation of membrane affinity in avian brush border and erythrocyte spectrins. $J$. Cell Biol. 101, 1379-1385.

IzZARD, C. S., and LOCHNER, L. R. (1980). Formation of cell-substrate contacts during fibroblast motility: An interference reflexion study. J. Cell Sci. 42, 81-116.

JACOBSON, A. G., OSTER, G. F., ODELL, G. M., and CHENG, L. Y. (1986). Neurulation and the cortical tractor model for epithelial folding. $J$. Embryol. Exp. Morphol. 96, 19-49.

Johnson, D. A., GAUTSCH, J. W., Sportsman, G. R., and Elder, G. H. (1984). Technique utilizing nonfat dry milk for analysis of proteins and nucleic acids transferred to nitrocellulose. Gene Anal. Technol. $1,3-8$.

JOHNSON, M. H. (1979). Intrinsic and extrinsic factors in preimplantation development. J. Reprod. Fertil. 55, 255-265.

Johnson, M. H., and MARo, B. (1984). The distribution of cytoplasmic actin in mouse 8-cell blastomeres. J. Embryol. Exp. Morphol. 82, 97-117.

KakiUChI, S., Sobue, K., KanaKa, K., Morimoto, K., Tsukati, J., Tsukita, S., IshIKAWA, M., and KarakaWA, M. (1982). Correlaive biochemical and morphological studies on brain calspectrin: $A$ spectrin-like calmodulin binding protein. Biomed. Res. 3, 400-410.

KaO, K. J., Sommer, J. R., and Pizzo, S. V. (1981). Modulation of platelet shape and membrane receptor binding by $\mathrm{Ca}^{++}$-calmodulin complex. Nature (London) 292, 82-84.

Keller, H. U., Barandun, S., Kistler, P., and Pluki, J. S. (1979). Locomotion and adhesion of neutrophil granulocytes. Effects of albumin, fibrinogen and gamma globulins studied by reflection contrast microscopy. Exp. Cell Res. 122, 351-362.

Kimber, S. J., and Surani, M. A. H. (1982). Spreading of blastomeres from eight-cell mouse embryos on lectin coated beads. J. Cell Sci. 56, 191-206.

KIMBER, S. J., SURANI, M. A. H., and BARTON, S. C. (1982). Interactions of blastomeres suggests changes in cell surface adhesiveness during the formation of inner cell mass and trophectoderm in the preimplantation mouse embryo. J. Embryol. Exp. Morphol. 70, 133-152.

LAEMMLI, U. K. (1970). Cleavage of structural proteins during the assembly of the head of bacteriophage $\mathrm{T}_{4}$. Nature (London) $\mathbf{2 7 7}$, 680-685.

LEHTONEN, E., and BADLEY, R. A. (1980). Localization of cytoskeletal protein in preimplantation mouse embryos. J. Embryol. Exp. Morphol. 55, 211-225.

LeVINE, J., and WillarD, M. (1981). Fodrin: Axonally transported polypeptides associated with the internal periphery of many cells. J. Cell Biol. 90, 631-643.

LEVINE, J., and WILLARD, M. (1983). Redistribution of fodrin (a component of the cortical cytoplasm) accompanying capping of cell surface molecules. Proc. Natl. Acad Sci. USA 80, 191-195.

LewIS, W. H. (1931). Locomotion of lymphocytes. Bull. Johns Hopkins Hosp. 49, 29-36.

LEwIS, W. H., and WRIGHT, E. S. (1935). On the early development of the mouse egg. Carnegie Inst. Contrib. Embryol 25, 115-143.

LOOR, F. (1981). Cell surface-cell cortex transmembranous interaction with special reference to lymphocyte functions. In "Cytoskeletal Elements and Plasma Membrane Organization" (G. Poste and G. S. Nicolson, Eds.), pp. 255-335, North Holland, Amsterdam.

LUX, S. E. (1979). Spectrin-actin membrane skeleton of normal and abnormal red blood cells. Semin. Hematol. 16, 21-55.

MANGEAT, P. H., and BuRRIDGE, K. (1983). Binding of HeLa spectrin to a specific HeLa membrane fraction. Cell Motility 3, 657-669.

Mangeat, P. H., and BuRRIDGE, K. (1984). Immunoprecipitation of nonerythrocyte spectrin within live cells following microinjection of specific antibodies: Relation to cytoskeletal structures. J. Cell Biol 98, 1363-1377.

MEaNS, A. R., and DEDMAN, J. R. (1980). Calmodulin-an intracellular calcium receptor. Nature (London) 285, 73-77.

NELSON, G. A., ANDREWS, M. L., and KarNovsky, M. J. (1983). Control of erythrocyte shape by calmodulin. J. Cell Biol. 96, 730-735.

PAKRASI, P. L., and DEY, S. K. (1984). Role of calmodulin in blastocyst formation in the mouse. J. Reprod. Fertil. 71, 513-517.

Palfrey, H. C., Schiebler, W., and Greengard, P. (1982). $\Lambda$ major calmodulin-binding protein common to various vertebrate tissues. Proc. Natl. Acad. Sci. USA 79, 3780-3784.

REIMA, I., and LEHTONEN, E. (1985). Localization of nonerythroid 
spectrin and actin in mouse oocytes and preimplantation embryos. Differentiation 30, 68-75.

Schatten, H., Cheney, R., Batczon, R., Willard, M., Cline, C., SimERLY, C., and SChatTEN, G. (1986). Localization of fodrin during fertilization and early development of sea urchin and mice. Dev. Biol. 118, 457-466.

SHIMO-OKA, T., and WATANABE, Y. (1981). Stimulation of actomyosin $\mathrm{Mg}^{2+}$-ATPase activity by a brain microtubule-associated protein fraction: High-molecular-weight-actin-binding protein is the stimulating factor. J. Biochem. 90, 1297-1307.

Slaughter, G. R., and Means, A. R. (1985). Quantitation and significance of ${ }^{125}$ I-calmodulin binding to myosin light chain kinase and phosphorylase distributed on polyacrylamide gels. Biochem. Biophys. Res. Commun. 126, 195-203.

SOBEL, J. S. (1983). Cell-cell contact modulation of myosin organization in the eary mouse embryo. Dev. Biol 100, 41-65.

SoBEL, J. S. (1984a). Myosin rings and spreading in mouse blastomeres. J. Cell Biol. 99, 1145-1150.

SoBEL, J. S. (1984b). Organization of plasma-membrane associated filaments during development of cell contacts in early mouse embryos. J. Cell Biol. 99, 36a.
SoBEL, J. S., and AlLIEGro, M. A. (1985). Changes in the distribution of a spectrin-like protein during development of the preimplantation mouse embryo. J. Cell Biol. 100, 333-336.

SOBEL, J. S., OPAS, M., and KalNins, V. I. (1985). Spectrin and cell contacts in the early mouse embryo. J. Cell Biol. 101, 1766a.

SobUe, K., Kanda, K., ADACHI, J., and KaKUichi, S. (1983). Calmodulin-binding proteins that interact with actin filaments in a $\mathrm{Ca}^{2+}$ dependent flip-flop manner: Survey in brain and secretory tissues. Proc. Natl. Acad. Sci. 80, 6868-6871.

SPiNDLE, A. (1980). An improved culture medium for mouse blastocysts. In Vitro 16, 669-674.

Sutherland, A. I., and Calarco-Gillam, P. G. (1983). Analysis of compaction in the preimplantation mouse embryo. Dev. Biol. 100, 328-338.

Towbin, H. T., Staehlin, T., and GoRdon, J. (1979). Electrophoretic transfer of proteins from polyacrylamide gels to nitrocellulose sheets: procedure and some applications. Proc. Nath Acad. Sci. USA 76, 4350-4354.

WAGNER, P. D. (1984). Calcium-sensitive modulation of the actomyosin ATPase by fodrin. $J$. Biol. Chem. 259, 6306-6310. 